\section{Towards understanding the causes of famine}

While there is universal sympathy for the faminestricken people living in the African Sahel, there is no universally accepted explanation of the causes. It is clear, however, that desertification has devastated large parts of 10 countries, stretching from Senegal and Mauritania in the west to Ethiopia and Somalia in the east.

One view is that the cause of the disaster is meteorological: a sequence of years in the 1970s with below average rainfall. Another view, put forward by A. R. E. Sinclair and J. M. Fryxell (1985) and discussed by J. Krebs and M. J. Coe (1985), is that desertification is man-made, resulting from a complex combination of demographic, cultural and agricultural changes exacerbated by ill-advised aid schemes and colonial development in the region.

They argue that the scene for the present disaster was set when development agencies began to drill boreholes in the semi-arid zones. This encouraged the migratory pastoralist inhabitants to discard their way of life in favour of a more settled one around the new, permanent sources of water. It is this disruption of a centuries-old, finely tuned adaptation to a semi-arid environment that has had the devastating effects we witness today.

Traditionally, the Sahel pastoralists followed a migration pattern resembling that exhibited by the wildebeest of the Serengeti Plains further south. These animals migrate annually from areas of high rainfall to semi-arid plains, with a rainfall comparable to that of the Sahel, where they graze on the seasonal flush of grasses that spring up after the rains. The food is of such high quality that the wildebeest calve in those areas, but as soon as the surface water disappears they trek back to their wetter homelands, to feed on taller, perennial, but lower-quality vegetation. This arrangement not only allows the wildebeest to exploit their environment to the full, but it also conserves the vegetation. When the wildebeest leave the semi-arid plains, the annual grasses have a chance to grow and set seed, and the perennial grasses have time to build up their reserves, before the moisture leaves the soil.

When the Sahel people stopped migrating and 2 settled with their cattle near the boreholes in the more arid parts of their range, the vegetation no longer had any respite from relentless year-round grazing. In addition, the new concentrations of people and cattle compacted the soil, reducing plant establishment. This effect was first noticed in the 1960s, before the low rainfall of the 1970s, which served only to hasten a process already begun. As the overgrazed area spread and coalesced, desertification proceeded in eamest.

Other exacerbating factors were also at work: pastoralists were discouraged from crossing national boundaries by the newly independent African States; medical and veterinary aid led to increase in human and cattle populations; and the traditional, wetter, grazing areas to the south were turned over to crops. The evidence leads to the view that the traditional migratory lifestyle is the most effective one for exploiting semi-arid Africa. To re-establish it would present enormous problems; the vegetation would take many years to recover and the human population has now grown far beyond the carrying capacity of the land under that kind of management. Whatever the inherent difficulties, however, it is essential that those who are trying so desperately to solve the problems of these peoples by aid and rehabilitation programmes take this ecological perspective into account.

\section{References}

Krebs, J.R. and Coe, M.J. Nature, 5 September 1985. Sinclair, A.R.E. and Fryxell, J.M. 1985. Can. J. Zool. 63, 987.

\section{Not quite a moratorium}

The International Whaling Commission's (IWC) moratorium on commercial whaling was due to commence at the time of writing-in October 1985 - at the beginning of what would have been the Antarctic whaling season. It is not, however, quite the moratorium that was hoped for because four whaling nations are, in their various ways, ignoring it-the USSR, Japan, Iceland and South Korea.

At the IWC's 37th annual meeting in July in Bournemouth, UK, the USSR, Japan and Norway remained formally opposed to the moratorium, but in its opening remarks the USSR

Oryx Vol 20 No 1, January 1986 
announced that it would stop commercial whaling by 1987, for technical reasons. It is understood that the USSR's Antarctic fleet is in a sorry state. Perhaps, too, the US sanctions, imposed when the USSR killed more than its quota of minke whales in 1984-85, by which the USSR lost 22,000 tonnes of fish from US waters, helped change its mind.

By the end of the meeting it was clear that Norway too would probably cease whaling, despite its objection. The stock of minke whales exploited by Norway in the north-east Atlantic is severely depleted. Previously unclassified, it was declared a protection stock at the meeting and a zero quota voted. Norway was thus committed to stop whaling because of its previous pledge to abide by the recommendations of the Scientific Committee of the IWC.

Japan's stock of sperm whales in the western Pacific was also reclassified as deserving protection, but Japan intended continuing whaling, regardless. It had gone against the decision of the IWC in 1984/85 and continued to take the sperm whales off the coast of Japan despite the zero quota. The US should have invoked sanctions against Japan for this contravention-it is required to do so under the Packwood-Magnuson Amendment to the Fishery Conservation and Management Act (1979). Instead, however, the US Government entered into a private agreement with Japan on 13 November 1984, under which Japan promised to withdraw its objection to the IWC's 1981 sperm whaling ban-with the withdrawal becoming effective in 1988. In exchange, the US agreed to allow Japanese whalers to take up to 400 sperm whales in 1984/85 and in $1985 / 86$ without invoking economic sanctions.

Aware of the probability of such an agreement being reached, on 8 November 1984 several conservation and animal welfare organizations filed suit in a US District Court against the Secretaries of Commerce and State, based on the premise that any commitment by them not to invoke sanctions against Japanese sperm whaling would be illegal. As the court case progressed, the original 10 plaintiffs were joined by three more environmental groups, and the Japanese Fishing and Whaling Associations became co-defendants with the Secretaries of Commerce and State.
On 5 March 1985 the US District Court ruled in favour of the organizations and ordered the US Government to certify Japan for its sperm whaling. The judge said: 'The Secretary of Commerce may not unilaterally, or even bilaterally with the Japanese, dismiss the mandate of the IWC so as to proceed with his own particular vision of whale preservation'. Japan recalled its Antarctic fleet and, with the US, appealed against the decision. On 6 August the US Court of Appeals confirmed the District Court's ruling, giving the US and the Japanese Whaling Association a 90-day stay of execution to allow them time for further appeals. On 18 September the US Justice Department, and on 20 September the Japanese Whaling Association, petitioned the full US Court of Appeals for a rehearing. We are yet to see the final outcome; if the US is forced to halve Japanese quotas in its waters, then Japan will have to choose between its fishermen and its whalers.

The IWC meeting ended without finding any way to stop Iceland and South Korea carrying on whaling. An IWC clause allows governments to grant themselves special permits to take any number of whales 'for the purpose of scientific research'. Both Iceland and South Korea announced that they would exploit this clause to avoid the moratorium, each taking 200 wales each year for the next four years. A proposal, by Switzerland and Sweden, that the sale of the whale meat from the 'research' should be forbidden, might have helped had it been accepted.

\section{Postscript}

In a letter to the IWC, dated 26 September 1985 the Philippines announced its intention of continuing taking Bryde's whales until 1988. There is no legal basis for this position; the Philippines abstained during the moratorium vote in 1982 and did not file an objection to the decision. This defiance of international law has far reaching implications for the continued existence of the IWC.

On 15 October the US Government was defeated for the third time when the full US Court of Appeals rejected its request for review of the Appeals Court ruling of 6 August. The US Government now has one option-to request a hearing by the Supreme Court. 


\section{CITES - the 5th Meeting of the Parties in Argentina: April/May 1985 by John A. Burton}

The Convention on International Trade in Endangered Species of Wild Fauna and Flora (CITES) was concluded at a meeting in Washington in 1973 and came into force after 10 countries had ratified it in 1975. Since then it has grown rapidly to become one of the most accepted international conventions in the world, with nearly 90 nations participating, including every country in South America. The reasons for the widespread acceptance of CITES are not fully understood-no doubt each country has its own special reasons for adopting it- but the fact that wildlife conservation became an important issue in the 1970s, together with the recognition by the developing countries that their wildlife resources should not be depleted, was most spectacularly obvious in the international trade. Smuggling of endangered wildlife became headline news. Tens of thousands of protected small cats, such as ocelots and margays, were being shipped from Brazil, where they were protected, to West Germany. Literally tons of coral were being illegally exported from the Philippines. Live parrots were squeezed into hair curlers, with their beaks taped down, packed in suitcases among clothing and smuggled from Australia. Pythons were smuggled out of Ghana, suitcases of endangered cacti were taken from Mexico to Germany. And more. Wildlife is big business, but the risks are a lot less than drug smuggling - and yet, by coincidence, many of the places involved deal in drugs and wildlife. Leticia, in Colombia, is a well-known centre of drug smuggling from Colombia to the USA, and also a major source of wildlife, both dead and alive. By the 1980s some of the worst aspects of the wildlife trade had been brought under control, and even those areas not yet totally under control were at least recognized and serious attempts were being made to regulate them.

In April/May 1985 the Parties to CITES met for their fifth biennial conference in Buenos Aires, Argentina, and the measures adopted there largely reflected the effectiveness of the Convention. Early in the meeting there was strong criticism of Bolivia, from whence it appeared that 4 large numbers of animals were being exported, many of which could have been smuggled from other countries. Huge numbers of forged permits were involved, and in a surprise resolution put forward by 12 South American Parties, it was agreed to reject all shipments originating in Bolivia until such time as they had organized their permit system effectively.

Another aspect of trade that has been very much in the public eye is ivory. In recognition of this, the Buenos Aires Conference agreed to establish a special Ivory Unit. Trade in ivory will be closely scrutinized and shipments will be accompanied by documents on specially printed security paper. It is hoped that this will reduce the amount of poached ivory that enters trade (estimated at up to 80 per cent in recent years).

One of the problems in controlling wildlife trade is that, as soon as one species is protected, another is likely to be exploited; in many European countries frogs are protected, and in any case high labour costs probably make capture uneconomic, consequently a substantial trade in Asian frogs has developed. As yet there is no evidence to suggest that any of the species is endangered, but the Conference decided to monitor them by listing them on Appendix II to the Convention (Appendix I is strict protection with no commercial trade, Appendix II less strict, but closely monitored trade).

However, not all of CITES's activities are banning and restricting trade. At the 5th meeting it was decided to relax the controls on the trade in Nile crocodile hide, but only in those countries that could demonstrate they had healthy crocodile populations and could control the trade effectively. Similarly, quotas for the trade in leopard skins were set for those countries with populations of leopards that were large enough to be actually causing problems with livestock.

By the time the Parties to CITES next meet in 1987 , there could well be nearly 100 Parties, and there is no doubt that it will be one of the most effective international treaties in existence. How it will operate in the future remains to be seen-it will doubtless continue to give protection to some species, and monitor the exploitation of others. While this is balanced, there is hope for the Oryx Vol 20 No 1, January 1986 
world's wildlife; pure protection will affect the developing countries adversely, but obviously too little protection will lead to the disappearance of the very wildlife upon which they may depend.

\section{Corals and clams for CITES by Sue Wells}

Despite considerable trade in invertebrates, CITES (Convention on International Trade in Endangered Species of Wild Flora and Fauna) has so far been little concerned with this group of animals. However, at the 5th Meeting of the Parties in Buenos Aires in April, there were some new invertebrate additions to the Appendices. Perhaps most importantly, the proposal by Australia to add 14 stony coral genera (the commoner corals involved in the ornamental coral trade) to Appendix II was accepted by 31 votes to 3 . Their addition could have a major impact. The majority of corals in trade, particularly in the UK, come from the Philippines, although collection and export has been prohibited since 1977. Enforcement has been a major problem, and there is widespread smuggling, corals being exported under the guise of shells and shellcraft. As Appendix II taxa, these corals will now require permits from the country of export and these of course should not be issued by the Philippine authority. It is to be hoped that enforcement will be rigorous as there is strong evidence to suggest that the coral trade has contributed to reef deterioration. Philippine coral collectors have been vociferous that their livelihoods would be threatened by the introduction of controls, but there is every reason to believe that much of their income comes from the collection of shells.

The exact impact of the CITES listing cannot be predicted. There is a possibility that the trade will turn to new sources of supply, but many countries with reefs are introducing legislation to prohibit or control coral collection. The genera that have been listed are largely Indo-Pacific and, to be comprehensive, Caribbean genera involved in the trade should be listed as well. One solution would be to list all stony corals (including genera in the orders Scleractinia (true stony corals), Athecata (fire corals), Coenothecalia (blue corals) News and views and Stolonifera (organpipe corals))

There could also be greater emphasis on the ornamental shell trade. Little information is available on the impact of shell collecting; some species seem to be able to support large regular harvests, but there are many anecdotal accounts that suggest that populations are being seriously depleted in some areas. The giant clams Tridacna spp. have declined through over-exploitation. At the last meeting of the Parties the two largest species, $T$. gigas and $T$. derasa, were added to Appendix II, and at this recent meeting the five remaining species were added. Although not particularly threatened themselves, their addition will eliminate problems of identification for Customs officers. Further research is urgently required on the ornamental shell trade and its long-term impact, particularly as this may expand following a reduction in the coral trade.

\section{Latin American conservation network founded}

Concern about wildlife conservation is increasing among Latin American peoples, and the number of non-governmental organizations (NGOs) concerned with conservation is growing. This encouraging development became very apparent at the 5th meeting of the Convention on International Trade in Endangered Species of Wild Fauna and Flora in Buenos Aires in April/May 1985. A Latin American network of conservation NGOs was founded and a 'Buenos Aires Declaration' was signed.

The network includes 12 organizations from Argentina, Bolivia, Brazil, Chile and Uruguay, and plans to promote action at regional and continental levels. A newsletter is to be published; its first issue was due in June 1985. (Editor, CIPFE-CED Orione, Dept. Biology, PO Box 13125, Montevideo, Uruguay.)

The Declaration was an open document distributed to everyone at the CITES meeting, which stated that 'the NGOs reaffirm their importance, facing environmental problems, from a democratic. independent and civilian perspective, in the defense of the development of our people and the execution of concrete actions; they ask 
for an interchange of information between all NGOs; request the end of the traffic in threatened and endangered Latin American wildlife, which depends not only on the countries of the region, which are undergoing a profound crisis, but also on the consumer nations that constantly stimulate the trade; and pointed out the need for global conservation actions facing the ecosystem as a whole'.

From a report by Eduardo Gudynas, FFPS correspondent in Uruguay.

\section{New move to save rhinos}

Rhino numbers continue to fall, despite antipoaching efforts, because the demand for the horn is so great. In North Yemen rhino hom is used for making dagger handles, and in eastern Asia rhino products are consumed as traditional medicines (not aphrodisiacs). African rhino horn sells for US $\$ 500$ wholesale per $\mathrm{kg}$, while Asian horn fetches US $\$ 9000$. Thus, the last large rhino strongholds are now being attacked by poachers.

Anti-poaching measures alone are obviously not enough to save rhinos in the wild. In July 1985 the World Wildlife Fund, with the assistance of the African Fund for Endangered Wildlife, started sponsoring a major international project to close down the trade in rhino products and to reduce the demand for the horn. The Project Director is Esmond Bradley Martin, who is also Vice-Chairman of the IUCN's African Elephant and Rhino Specialist Group, and the Project Co-ordinator is Lucy Vigne, formerly Executive Officer of the same group. An advisory body will be established to assist the project.

Rhino products are still imported legally into Singapore, Macao, Brunei and South Korea. Emphasis will be placed on persuading the senior government officials in these countries to ban rhino products and to enforce the law. In certain countries where rhino horn is illegal it is nevertheless still imported, as into North Yemen and Malaysia, and the governments of these countries must be asked to bring in stricter control measures. China and Japan manufacture medicines containing rhino horn, and this should be discouraged. Briefing documents will be sent to the appropriate political decision-makers in the various countries, and similar documents will be 6 circulated to importers and wholesalers of rhino products and also to the medical and pharmaceutical associations encouraging them to use substitutes for rhino hom such as the hom of the saiga antelope, a species that is not endangered. Esmond Bradley Martin will go to Asia for $4 \frac{1}{2}$ months to discuss ways of stopping the legal and illegal trade.

A strong public awareness effort, especially in Asia, will address the crisis of the rhino through newspapers, television, radio and public displays. Posters will be produced promoting substitutes for rhino products.

If the trade in rhino products can be banned and the demand for the horn be significantly reduced in conjunction with anti-poaching activities, the five rhino species may continue to live and breed in their natural habitat.

\section{The stonechat of Fuerteventura Island by Barry Phillips}

The Fuerteventura stonechat Saxicola dacotiae is listed as 'Rare' in the ICBP/IUCN Red Data Book (Collar and Stuart, 1985), and since its discovery in the late 19th century, information on its population and distribution has been fragmentary. In 1979 a general bird survey on the only island where the stonechat lives, Fuerteventura in the Canary Islands, suggested there were 50-150 pairs. Fewer casual records during a similar survey in 1984 led to concern about a possible decline in numbers. A project was set up to study the bird, supported by the Royal Society for the Protection of Birds, the Instituto Nacional para la Conservacion de la Naturaleza and the International Council for Bird Preservation.

Fuerteventura is the second largest island in the Canaries (1620 sq km), but the least populated. Lush and well-wooded 500 years ago, the landscape is now an arid mixture of stony plains, sand dunes and eroded mountain ranges. Low rainfall and overgrazing by goats prevent regeneration. In February 1985 an Anglo-Spanish group of ecologists arrived on Fuerteventura to begin an intensive study of the stonechat, in what the islanders described as the wettest spring for a decade. Most birds were already breeding, and the chats were very conspicuous, calling noisily

Oryx Vol 20 No 1, January 1986 


\section{News and views}

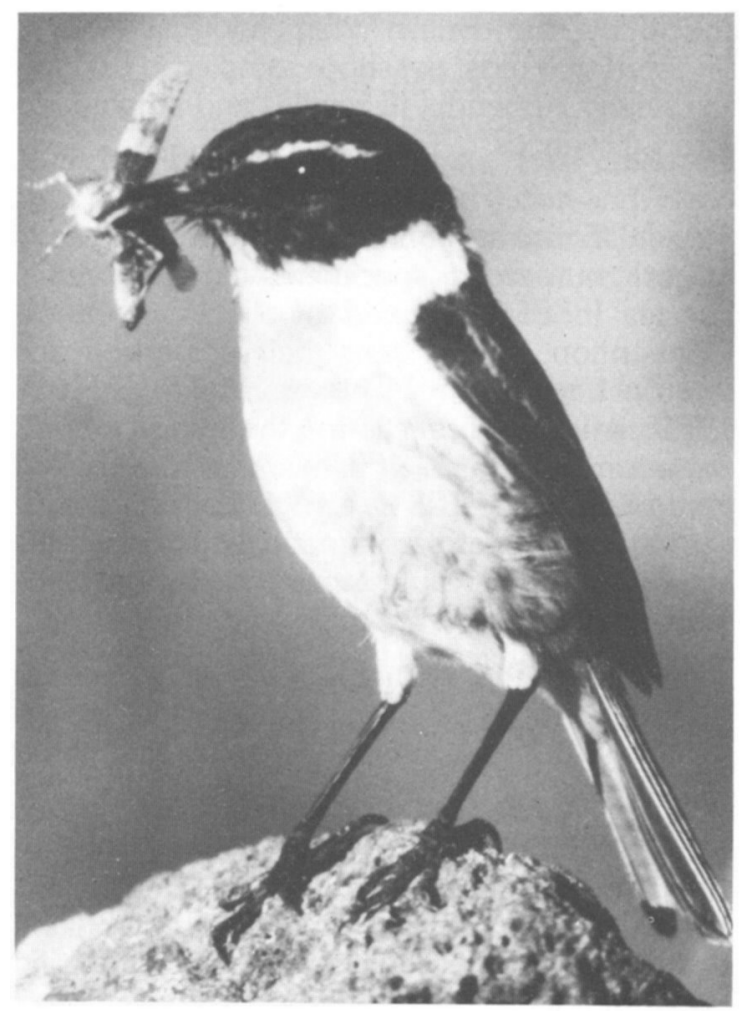

Fuerteventura stonechat (David Hill).

and frequently making aerial sallies to catch insects. We intensively searched randomly located sample plots, covering almost 13 per cent of the island, and found 75 pairs and 24 additional males. Assuming that our survey was 90 per cent efficient and half the extra males represented pairs, we estimated that the population in the spring of 1985 was $750 \pm 100$ pairs. Of the pairs found, 63 per cent had chicks and a few were accompanied by extra males-the lack of aggression suggests the possibility of co-operative breeding. While numbers were higher than suspected, not all suitable habitat was occupied. The chats appear to prefer terrain with fairly steep slopes, stony ground and some low scrub.

Fears that the chat might be declining appear to be unfounded. It is widespread on the island, and good concentrations occur in some of the most remote and inhospitable terrain. Agriculture has been declining since the 18th century and today most is at subsistence level. Tourism, although News and views developing rapidly and likely to become increasingly important in the island's economy, is not seen as a serious conservation problem. The continuing effects of desertification may, however, adversely affect the chat's future well-being.

As one of a handful of single island endemics in the western Palaearctic and one of the rarest birds in the region, the Fuerteventura stonechat merits further investigation. Having established a baseline census to monitor population trends, we intend to study its precise habitat requirements. We need to know why the bird is present in such low numbers in what is apparently suitable habitat. In 1986 we will begin studies on the influence of food supply and breeding success, and we are seeking sponsorship for a local student to undertake a long-term look at the biology of this intriguing bird.

\section{Reference}

Collar, N.J. and Stuart, S. 1985. Threatened Birds of Africa and Related Islands. The ICBP/IUCN Red Data Book, Part 1, 3rd edition. ICBP and IUCN, Cambridge.

\section{Britain failing to implement the Bern Convention}

When Britain ratified the Bern Convention (Convention on the Conservation of European Wildlife and Natural Habitats) in 1982, it took on a number of legal obligations. Now, more than three years later, it seems to have failed dismally to take effective action to protect many of the species listed on the Appendices to the Convention. The notable exceptions are the bats, all of which, except the common pipistrelle, are listed on Appendix II, and all of which receive effective and careful protection under the Wildlife and Countryside Act (1981).

Britain is to be congratulated on that, but the Act is intended to implement the Bern Convention in its entirety and this it does not do. This is partly because it gives insufficient protection to important sites for many of the Bern Convention species, by permitting the damage or destruction of breeding sites that are outside nature reserves or Sites of Special Scientfic Interest (SSSIs) if the act of damage or destruction is 'the incidental 
result of a lawful operation and could not reasonably have been avoided'. Thus, without fear of prosecution, water authorities can destroy otter holts, as the Welsh Water Authority did recently, in the course of routine clearance work, farmers can cut hay in meadows where corncrakes are breeding, and land developers can fill in the breeding ponds of great crested newts for housebuilding purposes. All these species are listed on Appendix II of the Bem Convention as requiring special protection.

A report published in September 1985 illustrates the deficiencies in the UK system of protection by describing how the comcrake, the merlin, the otter, the great crested newt and the smooth snake, just five of the Appendix II species, are faring in Britain. None is thriving, and this could be remedied in all cases by taking stronger measures to prevent the destruction of their habitats and by reducing the number of unnecessary deaths. Otters, for example, could be helped to recover by: making damage to their breeding and nesting sites illegal (as required by the Bern Convention) so that river authorities or land owners who knowingly damage holts can be prosecuted; passing, and enforcing, laws to require the use of otter-excluding devices on eeltraps; reducing the pollution of river systems; and by running a public education campaign to raise sympathy for otters, particularly among riverbank owners and users.

Appendix I of the Bern Convention deals with plants and contains only two species that occur in the UK: both sea lavenders. Appendix III, however, is of greater relevance. It lists commoner species of animals, which require less strict protection than those on Appendix II, whose exploitation needs regulation in order to keep their populations out of danger. The UK is not, according to the Report, implementing even these relatively limited obligations. For example, there is a total lack of control over the killing and collection of grass snakes, an Appendix III species known to be declining. The sale of Appendix III species, which includes common frogs, slow worms and toads, is theoretically controlled by a licensing system, but it does not work in practice. Few people apply for licences from the Department of the Environment (DOE) - the government body responsible for their issue - and a 8 check by the British Herpetological Society revealed that most pet shops sampled in London are selling Appendix III reptiles and amphibians without licences.

The DOE is also continuing to give licences to import numerous specimens of Appendix II species in contravention of Article 6e of the Convention, which bans their possession and internal trade. From 1 October 1984 to 31 March 1985, it issued licences for the import of 792 common wall lizards, 400 Italian wall lizards, 300 green lizards and 103 tree frogs. The report ends with a set of clear recommendations, which the UK Government would do well to act upon. Summarized, they are:

to direct the Nature Conservancy Council (NCC) to prepare an inventory of all important sites for Appendix II species and either designate them as SSSIs or amend the Wildlife and Countryside Act to grant them protection, even if they are outside nature reserves or SSSIs;

to direct the NCC to identify the threats facing Appendix II species and to prepare a plan for counteracting them;

to direct the NCC to identify all Appendix III species that have forms at risk locally in the UK, to protect them, and in particular to take immediate action to safeguard the Merseyside population of sand lizard;

to institute an effective licensing system to control the exploitation of Appendix III species;

to ensure that the NCC has sufficient resources to undertake the work referred to and to re-notify SSSIs and to notify proposed SSSIs important to Appendix II and III species;

to make the preparation of an environmental impact assessment mandatory prior to financing projects abroad that could affect species covered by the Convention.

\section{References}

Lyster, S. 1985. European Wildlife Convention: Report on the Problems in the UK. For Wildlife Link, 45 Shelton Street, London WC2H 9HJ, UK.

Oryx Vol 20 No 1, January 1986 


\section{The pigs that migrate}

The bearded pig Sus barbatus barbatus is an important and favourite food for many people in interior Borneo. Its ecology has challenged generations of zoologists, and Julian and Serena Caldecott, who have been trying to unravel its intricacies, have written about their recent findings in New Scientist (15 August 1985).

The pig is sometimes sedentary and sometimes roams widely, occasionally in huge herds. But what governs these movements and changes in population size? The Caldecotts have been able to construct a picture of the main events in a bearded pig population in northern Sarawak in the recent past from a number of disparate sources: the memories of tribal people who hunt the pig; the entries relating to pork and forest fruit purchases in the accounts of hundreds of small schools scattered throughout the interior; and export figures for illipe nuts (a collective name for the oily seeds of some dipterocarp trees), which are used in a number of industrial processes, including the manufacture of chocolate, and are also eaten by the pigs.

As the Caldecotts pursued their enquiries, a complicated story unfolded. It appears that 1983 saw a massive explosion in the bearded pig population, rivalled only by one remembered by hunters in 1959. Both were accompanied by consecutive years of remarkably prolific fruiting of dipterocarp trees-in 1958 and 1959, and in 1980,1981 , and 1983 . The pigs seem to reproduce faster when these oily seeds are abundant, and because the fruiting peaks are not fully synchronized between different areas, the pigs can exploit the seeds over a long period by migrating up and down mountains and between river valleys, from one peak of fruit to another. If there is one good fruiting year, these movements allow the pigs to maintain a momentum of growth and reproduction; if there are two or more consecutive good years, a massive population may result.

Following in the tracks of the bearded pig population of the upper Baram River, the Caldecotts traced a migration cycle that began and ended in the rich oak forests of a mountain ridge on the News and views border between Sarawak and Kalimantan. In early 1983 the population of pigs feeding on the acorns of this forest was already large from three consecutive years of good dipterocarp fruiting. They were sustained throughout their year-long journey, on a cycle that encompassed 10,000 sq $\mathrm{km}$, by not only another good dipterocarp crop but also by a bumper crop of non-dipterocarp fruits. On the way perhaps 20,000 were slaughtered for food, 8 per cent of the total estimated 250,000 for that population.

There is no way of telling when the next eruption of pigs might be. It will depend on the dipterocarp fruiting cycle, and that could soon be disrupted for ever in that area of Sarawak. In the next 10 years most of the upper Baram will probably be logged. Logging will alter the flowering and fruiting of rain-forest trees as well as removing a large proportion of dipterocarps, which are important timber trees. In many parts of Sarawak bearded pigs have virtually disappeared after logging. It is possible that the peoples of the Baram have seen the last of the bearded pigs' mass migrations.

\section{Giant clams extinct in Fiji?}

Giant clams seem to have almost disappeared from Fijian waters, according to preliminary results from a survey by ACIAR (Australian Center for International Agricultural Research) and ICLARM (International Center for Living and Aquatic Resources). The last known specimen of the largest species, Tridacna gigas, was taken 15 years ago, but now all species have declined, even on isolated uninhabited reef systems.

The cause is poaching by people from South East Asia, who have been forced east by the depletion of stocks in the Indo-West Pacific, and the intensive policing of Australian waters. The diary of a Taiwanese skipper was confiscated during an incident in Australian waters. One entry read, 'Reefs to the north of Australia and east at least as far as Fiji have been fished out-the only place with clams of any size and quantity is Australia'. As a fisheries officer in Fiji commented, 'There you have it-straight from the pen of one of the most experienced field-surveyors in the Pacific'. From a report by Sue Wells of the IUCN Conservation Monitoring Centre, Cambridge, UK. 